\title{
New lycosoid spiders from cave and surface habitats in southern Australia and Cape Range peninsula (Araneae: Lycosoidea)
}

\author{
Michael R. Gray ${ }^{1}$ and Judith A. Thompson ${ }^{2}$ \\ 'Australian Museum, 6 College Street, Sydney, New South Wales 2010, Australia \\ 222 Warrnambool Street, Trinity Park, Queensland 4879, Australia
}

\begin{abstract}
Two new genera of lycosoid spiders (Araneae: Lycosoidea) from Australian cave and surface habitats are described. The monotypic genus Bengalla gen. nov. is erected for B. bertmaini sp. nov., a blind troglobite from Cape Range peninsula, Western Australia. Huntia gen. nov. is erected for $H$. deepensis sp. nov., an epigean species from south-western Australia; and $H$. murrindal sp.nov., a troglobite with reduced eyes from south-eastern Australia. The relationships of both these genera and Janusia Gray, a putative lycosoid troglobite from the Nullarbor Plain, are discussed.
\end{abstract}

\section{INTRODUCTION}

The ecribellate spiders examined here are associated with the tengellid-zorocratid-lycosoid complex of Griswold (1993) and Griswold et al. (1999). This is a large assemblage of both cribellate and ecribellate spiders whose Australian representatives are numerous but contain many groups that are poorly known or understood. Among the structural features that characterise representatives of this complex are the subtegular/ tegular locking lobes, made up of opposing lobes on the subtegulum and tegulum of the male palp; and the tibial crack, an annular suture at the base of the leg tibiae in males. Another significant character, the presence of a grate-shaped tapetum in the indirect eyes, could not be resolved for the material available in this study.

Two of the species described here are obligate cave dwellers, while the epigean species is known only from forests in south-western Australia. They are of importance faunistically as short range endemic species of conservation and zoogeographic significance. Their relationships are of considerable interest, including possible affinities to Janusia Gray, an enigmatic troglobitic species from the Nullarbor Plain (Gray, 1973), currently placed provisionally in the family Ctenidae. The recognition of new genera here is deemed appropriate given the difficulty of assigning the species described to available genera.

\section{MATERIALS AND METHODS}

Specimen examinations, measurements and drawings were made using a Wild M5 microscope with graticule and drawing attachment. Epigynal preparations were cleared in $8 \%$ potassium hydroxide before mounting in glycerol for microscopic examination. Specimen preparations for scanning electron microscopy were air dried from $100 \%$ acetone.

\section{Terminology and abbreviations}

The term "plicate" is used to describe the pleatlike transverse ridges on the trichobothrial bases. CL carapace length; CW carapace width; STC superior tarsal claw; ITC inferior tarsal claw; RTA retrolateral tibial apophysis; ALS anterior lateral spinnerets; PMS posterior median spinnerets; PLS posterior lateral spinnerets.

\section{Repository institutions}

AMS, Australian Museum, Sydney; SAM, South Australian Museum, Adelaide; WAM, Western Australian Museum, Perth.

\section{SYSTEMATICS}

Bengalla gen. nov.

\section{Type Species}

Bengalla bertmaini sp. nov.

\section{Description}

Ecribellate hunting spiders. Body length 6-9.5 $\mathrm{mm}$. The only known species is an eyeless, unpigmented troglobite. Fovea a deep slit. Labium moderately long, with deep basal notches. Lateral maxillae margins weakly concave. Cheliceral groove margins with three to four teeth. Legs long. Trochanters deeply notched. Anterior tibiae with four to six pairs of ventral spines. Tibial crack absent. Tarsal organ subdistal, with a triangular, "keyhole derivative type" orifice. Trichobothria of similar length, in 
a

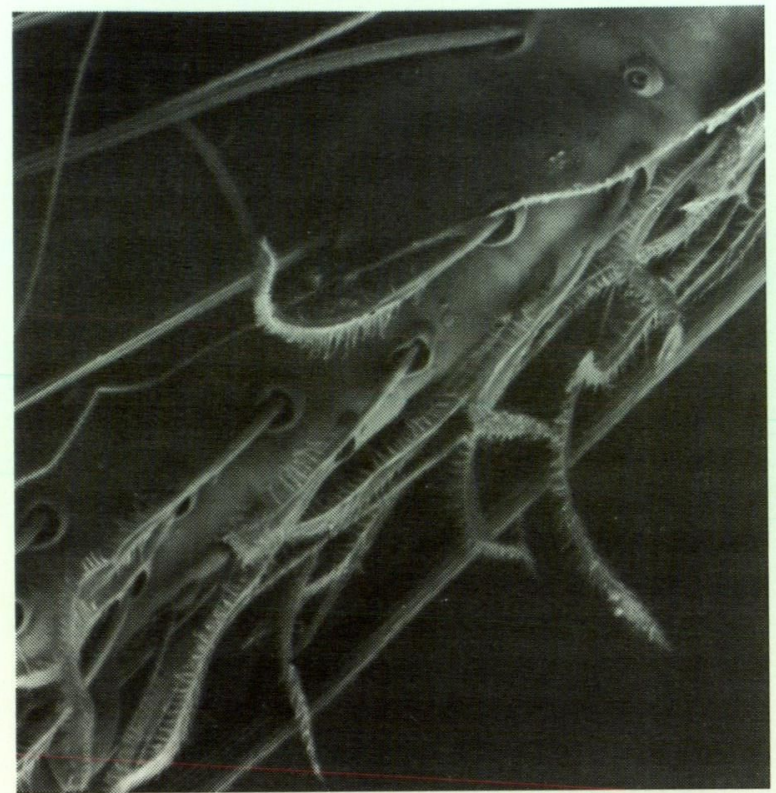

b

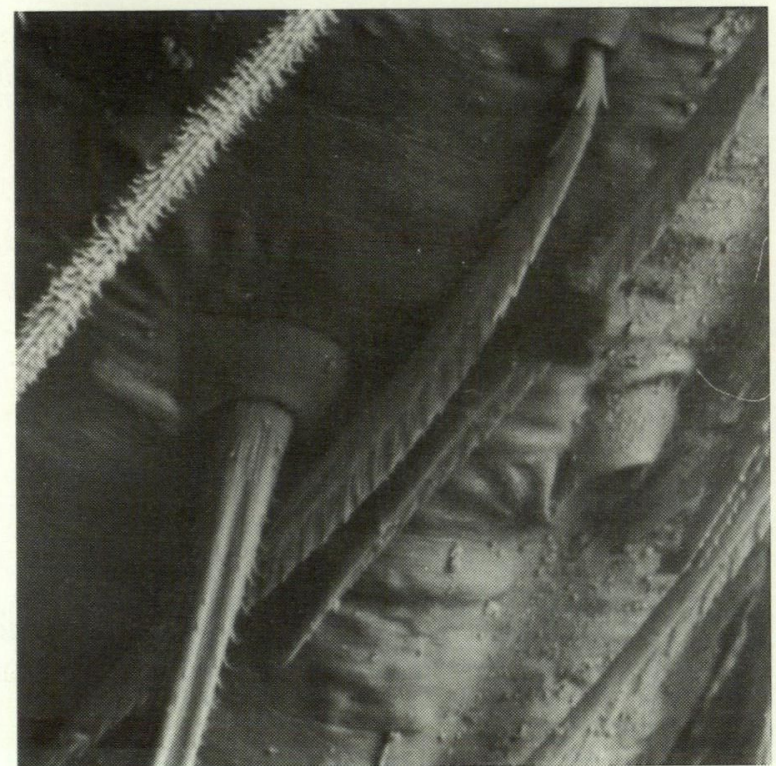

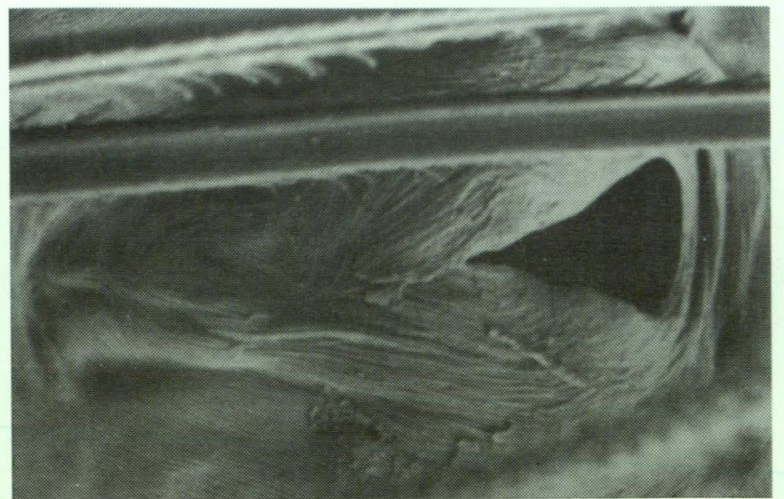

C
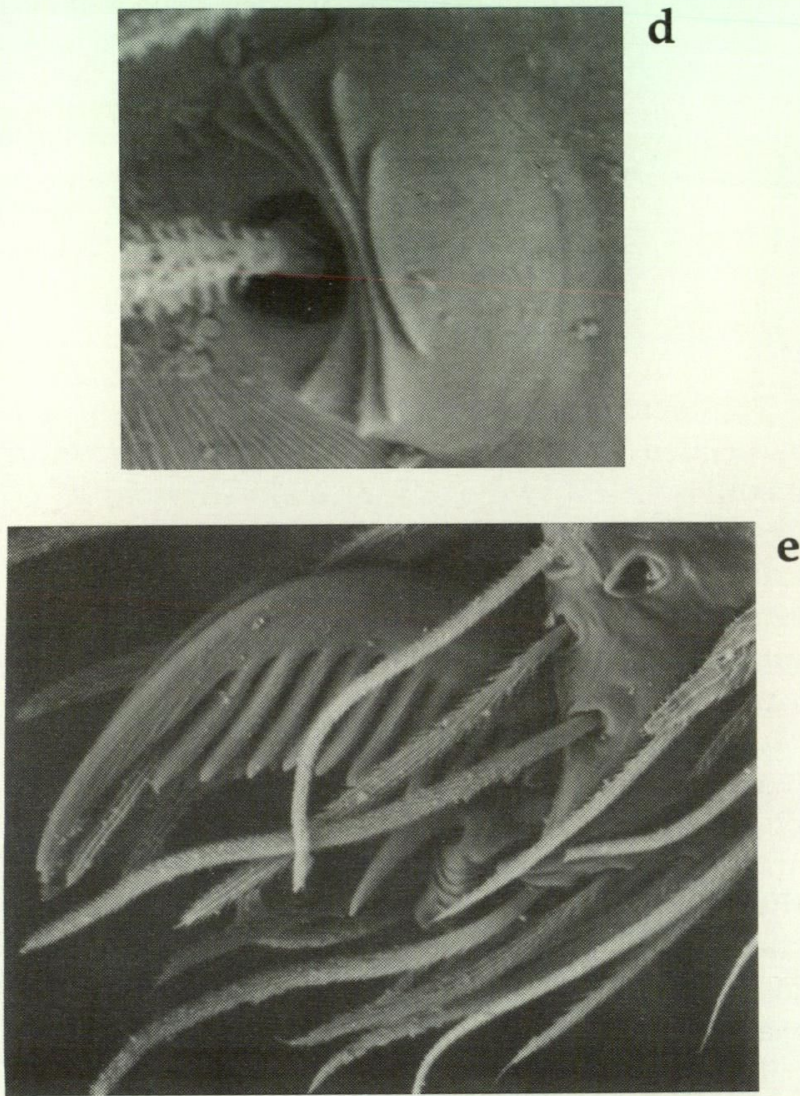

Figure 1 Bengalla bertmaini sp. nov., tarsus I: a, scopula setae; b, serrate setae; c, tarsal organ; d, trichobothrium base; e, tarsal claws.

two rows on tarsi and metatarsi; bases transversely plicate. Claw tufts absent, tarsi and metatarsi finely scopulate. ITC reduced on legs 1 , 2 and absent on legs 3, 4. Setae simple and plumose (sensu Lehtinen, 1975); tarsi and metatarsi with flattened, recumbent, lanceolate, serrate setae, serrations on one side only; feathery hairs absent. Prolateral and retrolateral femora with pink to mauve iridescence. Male palpal tibia long, with an apical, plate-like retroventral apophysis and a widely bifid retrolateral apophysis. Cymbium short, ovoid, with marked retrobasal groove. Subtegular/tegular locking lobes present, but weakly developed. Median apophysis long, prolateral surface concave, longitudinally oriented. Embolus an elongate, slender spine. Conductor a gently curved process arising proapically, base fleshy, becoming a hyaline lamina distally. Epigynum with a broad, 'wing-like' scape, narrowest basally; sides concave anterolaterally. Lateral lobes with a pair of lobules that extend to the epigastric groove. Six spinnerets. ALS 2-segmented with 2 major ampullate spigots and 15-17 piriform spigots. PMS 1-segmented, spigots interpreted as 3 cylindrical, 4 aciniform and 1 minor ampullate, plus 3 other medium sized spigots. PLS 2-segmented, apical area only visible with 1 cylindrical and several aciniform spigots. 


\section{Relationships}

Monotypic genera like Bengalla, that are represented by highly cave-adapted species, can pose particular difficulties in the assessment of their relationships. For example, the absence of eyes removes an important set of features normally used in characterising lycosoids and their kin. The genus Janusia, described for an eyeless female spider from the Nullarbor caves of Western Australia, has presented similar problems, further exacerbated by the absence of male specimens. Gray (1973) placed Janusia provisionally within the Machadoninae (sensu Lehtinen, 1967), mainly on the basis of epigynal similarities with the Sri Lankan genus Devendra Lehtinen. Most of Lehtinen's machadonine genera are now placed within the "ctenoid complex" of Griswold (1993). Possible affinity of Bengalla with Janusia is suggested by their possession of deeply notched trochanters; reduction or loss of the ITC; absence of claw tufts (the latter were erroneously noted as present in Janusia by Gray (1973); tarsal and metatarsal scopulae are present in Bengalla, but putative leg scopulae in Janusia are limited to the distal tarsi); and most notably, by the possession of a slender embolus. Gray (1973) observed the broken distal portion of a slender, wire-like embolus in a copulatory duct of the female type specimen. Within the tenellidzorocratid-lycosoid complex of Griswold (1993) a slender embolus has been recorded in the zorocratids, Acanthoctenus and the 'higher lycosoids'. This type of embolus is also seen in the Australian genus Leptoctenus L. Koch (L. agelenoides from Queensland) and Anahita Karsch (Diana Silva, personal communication). Both of these genera are currently referred to the Ctenidae. The other unusual character in Bengalla is the presence of epigynal lobules rather than teeth. However, this feature also occurs elsewhere and may not necessarily be unique at generic level. Silva (personal communication) has noted that either lobules or teeth can be present on the lateral lobes in species of both Anahita and Leptoctenus. The relationship of these genera with Janusia and Bengalla merits further consideration. a

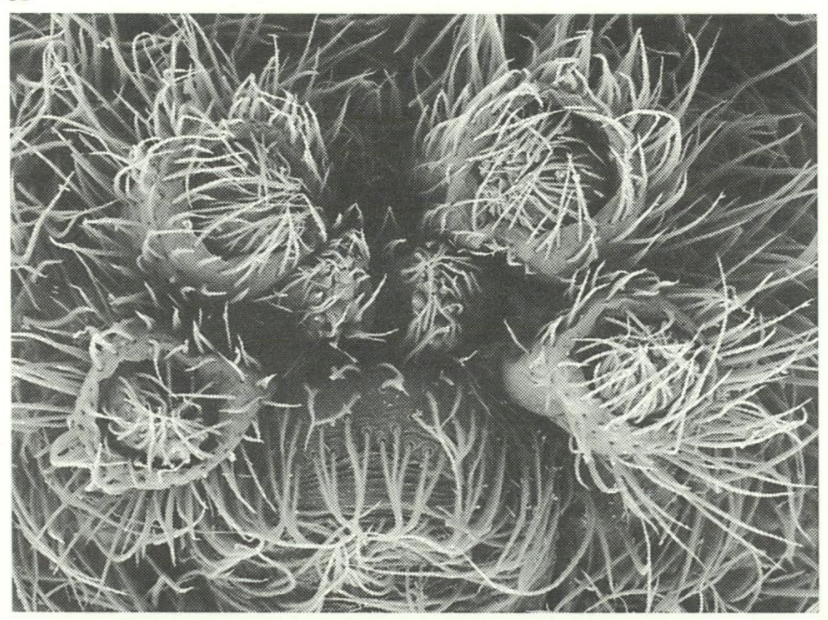

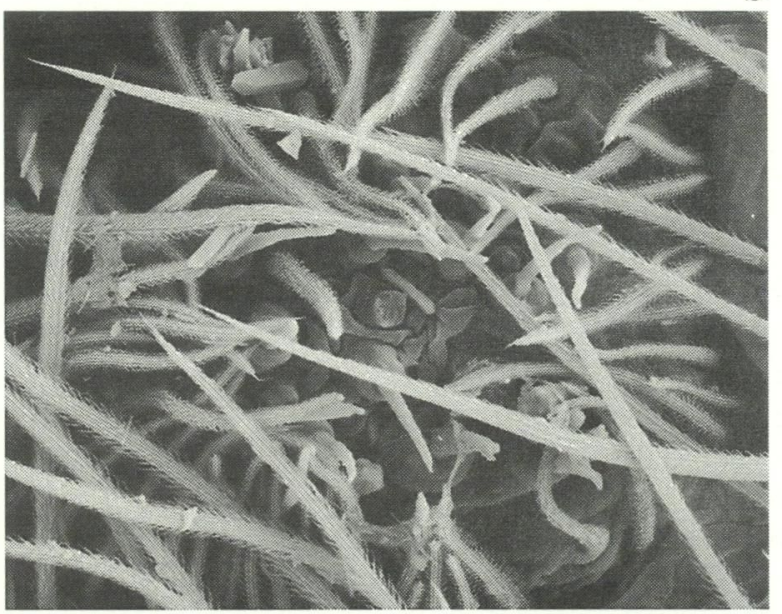

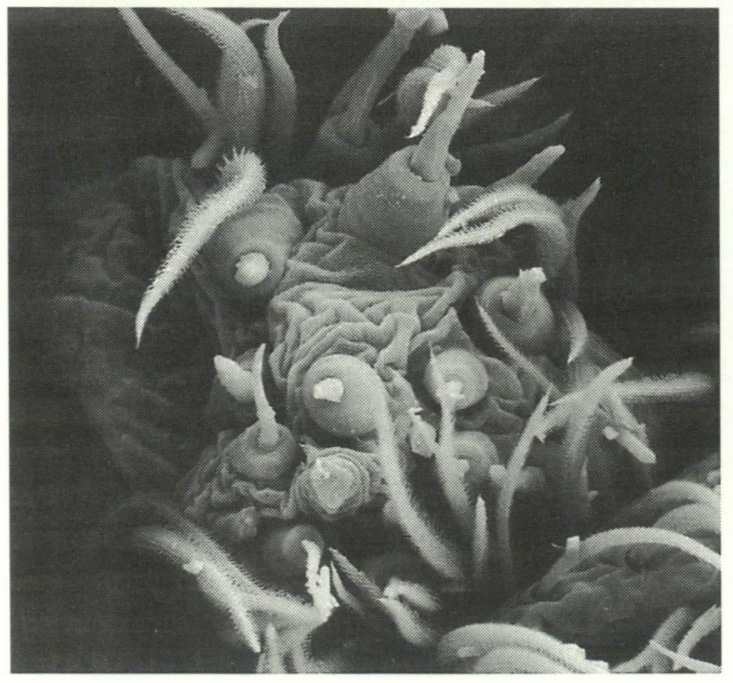

C

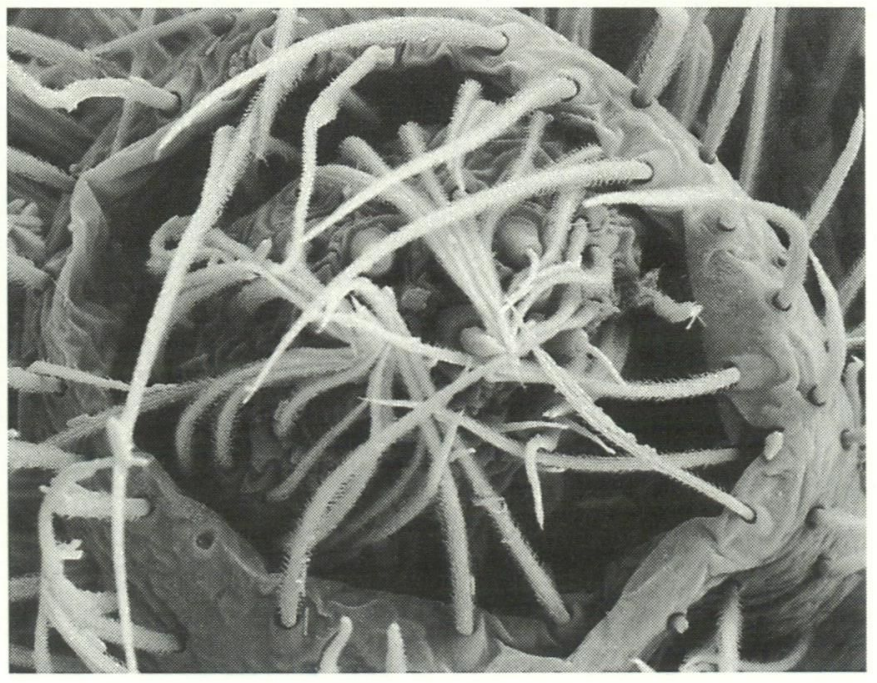

d

Figure 2 Bengalla bertmaini sp. nov., spinnerets (female): a, spinneret field; b, anterior lateral spinneret; c, posterior median spinneret; $d$, posterior lateral spinneret. 


\section{Etymology}

Bengalla is an Aboriginal word for "ornament". Here it refers to the striking pink iridescence on the femora of these spiders. The gender is male.

Bengalla bertmaini sp. nov.

Figures $1 \mathrm{a}-\mathrm{e}, 2 \mathrm{a}-\mathrm{d}, 3 \mathrm{a}-\mathrm{f}$

\section{Material Examined}

\section{Holotype}

ð, Cave C.65, Cape Range peninsula, Western Australia, Australia, $22^{\circ} 06^{\prime} \mathrm{S}, 114^{\circ} 00^{\prime} \mathrm{E}, 18$ August 1992, D. Brooks - BES 683 (WAM 92/1961).

\section{Paratypes}

Australia: Western Australia: Cape Range peninsula: 1 \& Cave C.126, 1989, S. Eberhard (AMS KS 21585); 1 오, Cave C. $167,22^{\circ} 09^{\prime} \mathrm{S}, 114^{\circ} 00^{\prime} \mathrm{E}, 20$ June 1989, M.S. Harvey (\#3994) (WAM 94/22); 1 , Cave C.118, 22 ${ }^{\circ} 09^{\prime} \mathrm{S}, 113^{\circ} 59^{\prime} \mathrm{E}, 21$ June 1989, W.F. Humphreys (\#3637) (WAM 94/23); 1 \&, Cave C.21, $22^{\circ} 14^{\prime} \mathrm{S}, 113^{\circ} 58^{\prime} \mathrm{E}, 10$ July 1989 , R. Wood and A. Humphreys (\#3377) (WAM 94/21); 1 \%, Cave C. $169,22^{\circ} 06^{\prime} \mathrm{S}, 114^{\circ} 00^{\prime} \mathrm{E}, 26$ June 1989, A. Humphreys (\#3821) (WAM 94/24); 1 \&, Cave C.18, 13 August 1988, W.F. Humphreys et al. (WAM 94/ 19).

\section{Diagnosis}

Eyes and pigment absent. Legs long, lateral femora with pinkish iridescence. Claw tufts absent, tarsi and metatarsi finely scopulate. ITC small (legs I, II) or absent. Epigynum with a pair of lateral lobules. Male palpal RTA widely bifurcate with two slender processes. Embolus long, slender.

\section{Description}

\section{Male holotype}

Body length 6.17. CL 3.06, CW 2.37. Caput profile almost flat, inclined slightly upward to fovea. Chelicerae slender. Legs 4123 , very long, tibia I length 1.86 times CW. Spination: leg I, femur d01101 p01111 r 01111, tibia v112222 p $001101010 \mathrm{r}$ 111 , metatarsus d010 v2112 p111 r111; leg II, femur d0111 p0111 r01111, patella p010, r010, tibia v22222 p01110 r01011010, metatarsus d012, v222, p111, r111; leg III, femur d0111 p01111 r11111, patella p010 r010, tibia v222 p0110 r1110, metatarsus d022 v221 p111 r111; leg IV, femur d0111 p011011 r00111, patella p010 r010, tibia d10011 v0200202 p00110 r00110, metatarsus d011 v1101011001 p111 r1101. Palpal tibia long, with two apophyses: an apical, retroventral plate and a subapical, widely bifid RTA made up of slender, curved retrolateral and retrodorsal processes (the former thickest), connected basally by a low ridge. Cymbium short, ovoid, without scopulate hair patch. Subtegular/ tegular locking lobes only weakly developed. Median apophysis elongate, concave, arising on the retrolateral side of the middle tegulum. Embolus a slender, tapering spine, arising retrobasally. Conductor fleshy basally and mildly curved and twisted apically as a hyaline lamina supporting the thin distal embolus; apical conductor extends beyond the cymbium apex. Other characters similar to female.

\section{Female paratype (KS 21585)}

Body length 9.01. CL 4.94, CW 3.89. Unpigmented spiders. Legs and carapace light amber, somewhat darker toward front of caput and on chelicerae. Abdomen cream coloured. Caput profile gently arched back to anterior fovea, flattened in foveal region. Fovea a deep, moderately long slit. Chilum divided. Eyes absent, lateral ocular area with ridge marking former position of lateral eyes. Chelicerae robust, with a large, lateral boss. Cheliceral retromargin and promargin with 3-4 teeth. Labium longer than wide (1:0.78), flat, with basolateral grooves opposite long basal notches. Maxillae moderately long, anterolateral margins gently concave. Sternum longer than wide (1:0.80), weakly pointed posteriorly. Legs 4123 , long, tibia I length 1.47 times CW. Cuticle finely wrinkled. Trochanters deeply notched. Spination: leg I, femur d010101 p0011 or 201 r01111, tibia v202222, metatarsus v0222; leg II, femur d01101 p01111 r0111001, patella r010, tibia v2202222 r010100, metatarsus v0222; leg III femur d01101 p01111 r01111, patella p010 r010, tibia d1001010 v2022 p00110 r00110, metatarsus d022 v222 p111 r1110; leg IV, femur d010101 p0110101 r0001101, patella p0100 r010, tibia d10011 v2022 p00110 r0110, metatarsus d2102 v01101 p111 r00101. Tibial and metatarsal spines long. Tarsi and metatarsi with weak scopulae. Claw tufts absent. STC with 5-6 teeth. ITC reduced on legs I, II and absent on legs III, IV. Tarsal organ capsulate, placed distal to trichobothria; orifice triangular, broadest distally, tapering to a short, relatively wide, proximal slit. Trichobothria long, in two rows on tarsus and metatarsus. Trichobothrial base plicate with 3-5 transverse ridges. Colulus indistinct. ALS and PLS short, similar in length, PMS about half as long as PLS. Epigynal scape wide, with'wing-like' lateral extensions spreading from a narrower basal attachment; anterolateral scape margins deeply concave. Lateral lobes with a pair of narrow lobules extending posteromedially to the epigastric groove. Lobules moderately flattened and translucent basally, each becoming paler and more opaque toward the bluntly rounded apices; attached basally along posterior part of the lateral epigynal groove, overlapping the posterolateral scape margin. Internal genitalia receptaculate; copulatory ducts short and curved, apparently opening from tapering atrial cavities under the anterolateral margins of the scape. 


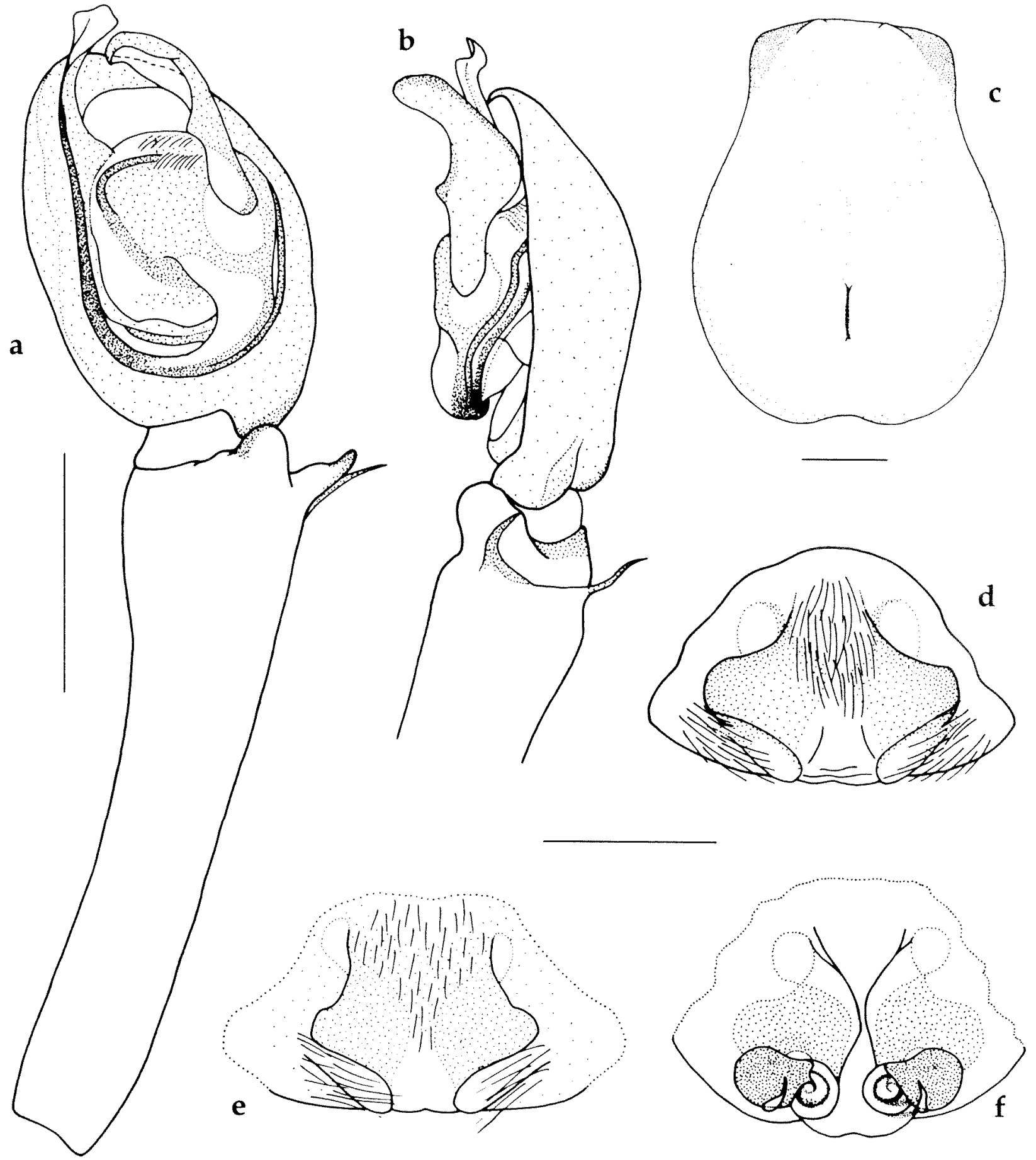

Figure 3 Bengalla bertmaini sp. nov. a, b, male palp: tibia, cymbium and bulb: a, ventral; b, retrolateral. $c$, carapace, female. d-f epigynum: d, e, ventral; f, dorsal. Scale lines: $a, b, d-f, 0.5 \mathrm{~mm} ; \mathrm{c}, 1 \mathrm{~mm}$.

\section{Variation}

Width of basal attachment of epigynal scape ranges from one-fifth to two-thirds of the scape width.

\section{Distribution}

This troglobitic species is confined to the caves of the Cape Range peninsula, Western Australia.

\section{Remarks}

Specimens of Bengalla bertmaini were collected as part of a biogeographic study of the caves of Cape Range peninsula, Western Australia (Humphreys, 1993, Harvey et al., 1993). These blind, long-legged, tactile hunters are relatively common in the deeper regions of the caves, where they feed upon other arthropods that make up the diverse troglobitic fauna of those cave systems.

\section{Etymology}

The species is named for Emeritus Professor of Zoology, A.R. (Bert) Main. 
Huntia gen. nov.

\section{Type Species}

Huntia deepensis sp. nov.

\section{Description}

Ecribellate hunting spiders. Body length $8-10$ $\mathrm{mm}$. Eyes in two rows: from above both are gently recurved; from in front AER straight, PER weakly procurved. AME smallest. Fovea short. Cheliceral margins with 3-4 teeth. Labium longer than wide with deep basal notches. Maxillae with weakly concave anterolateral margins. Sternum subcircular. Trochanters notched. Male legs with tibial crack. Anterior legs with 4 pairs of tibial spines. Claw tufts absent, tarsi with weak scopulae. ITC vestigial-absent. Setae simple and plumose (sensu Lehtinen 1975), feathery hairs absent. Tarsal organ placed subdistally, capsulate with a keyhole-type orifice. Trichobothria of similar length, in two rows on tarsi and metatarsi; base transversely plicate; Male palp with a small apical ventral apophysis and a large RTA, placed dorsad. Cymbium ovoid, tapering to a short, blunt apex; a dorsal scopula of short, fine hairs and a small, basodorsal apophysis are present. Subtegular/tegular lock present. Median apophysis large, prolaterally side deeply concave and bimarginate. Embolus a robust, curved, moderately flattened rod. Conductor a subapical, hyaline lamina. Epigynum with a broad scape, narrow at base, sides rounded; lateral teeth large. Six spinnerets: ALS 2-jointed with 2 major ampullate and 22 piriform spigots; PMS 1-jointed, spigots interpreted as 3-4 cylindrical, 1 minor ampullate, 15-17 aciniform; PLS 2-jointed, with 1 cylindrical spigot and many aciniform spigots (apical area only visible).

\section{Variation}

Huntia murrindal sp. nov. has a longer fovea; 5-6 pairs of tibial spines; ITC are present; tarsal organs are rod-like and more proximally placed (see "Comments" under this species regarding its generic placement). a
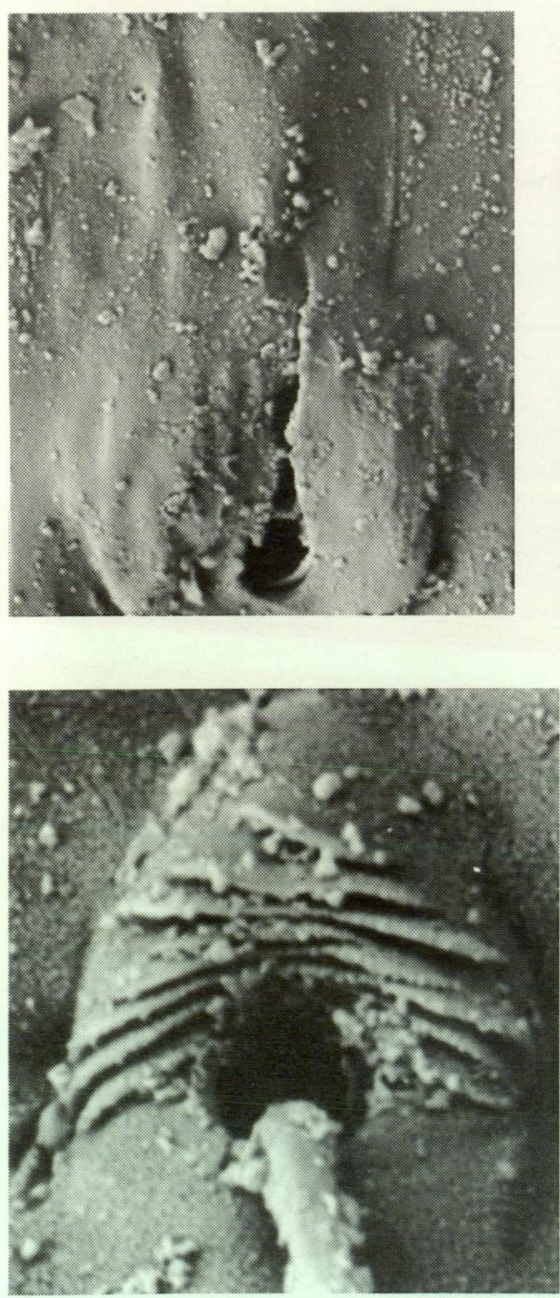

b c
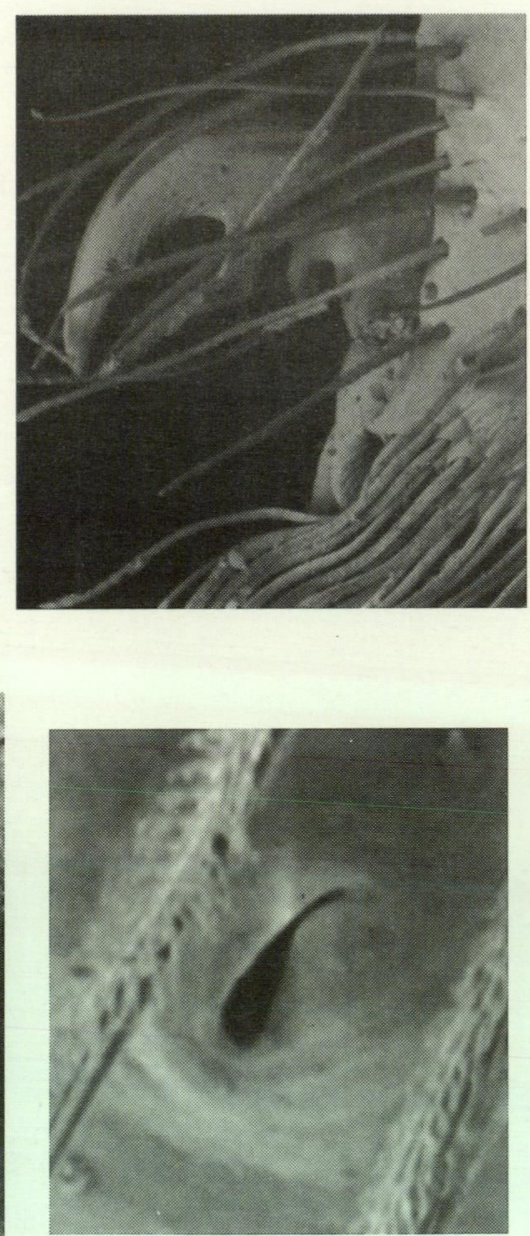

d e
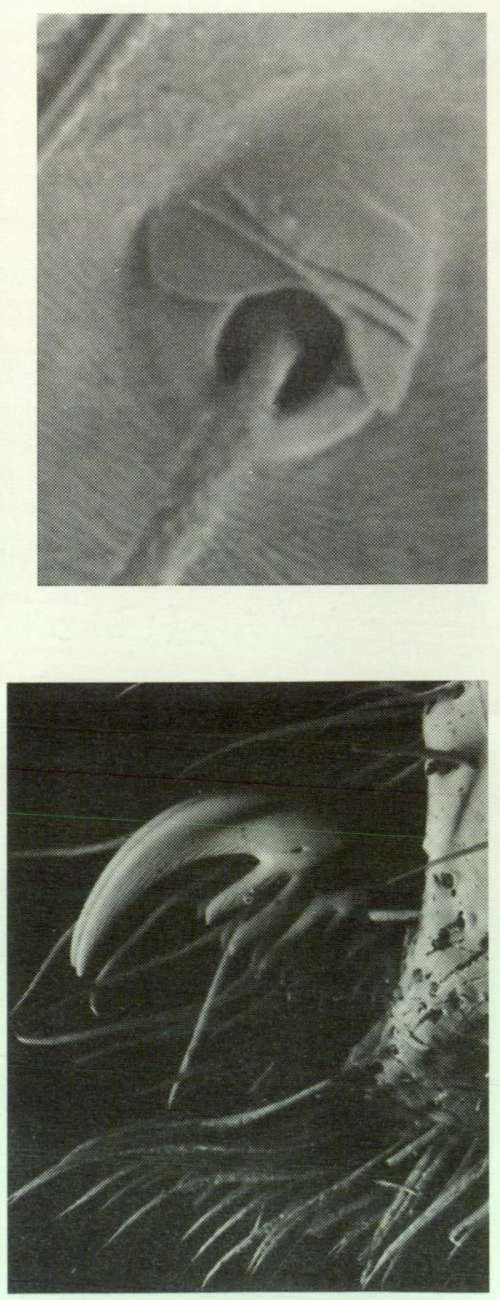

f

Figure 4 a-c, Janusia muiri Gray, d-f, Huntia deepensis sp. nov., tarsus I: a, d, tarsal organ; b, e, trichobothrial base; $c$, f, tarsal claws. 


\section{Relationships}

Based upon the character distribution of the tibial crack, a basal suture line found on the male leg tibiae (Griswold, 1991, 1993), it is likely that the ecribellate genus Huntia belongs either with the mostly cribellate Zorocratidae and Zoropsidae or the entirely ecribellate "ctenoid complex" of Griswold (1993). A longer labium and the absence of claw tufts suggests that Huntia is not a zoropsid. Its male palpal structure, with a large RTA, flattened embolus and deeply concave median apophysis, resembles the pattern seen in both the African zorocratid genus Raecius and ctenoid genera such as Devendra from Sri Lanka and Machadonia from southern Africa. The inclusion of Huntia in any of those genera seems precluded by one or more of the following characters: the presence of a keyhole shaped tarsal organ, a bimarginate median apophysis and a basodorsal cymbial apophysis. A bimarginate median apophysis is found only in genera of the "ctenoid complex", with the exception of Devendra. A basodorsal cymbial apophysis is recorded in the zorocratid genus Zorodictyna and the ctenoid genus Ctenus (Griswold, 1993). Taken together, the characters of Huntia noted above, along with the presence of two recurved eye rows and epigynal teeth, suggest that this genus belongs near Machadonia in Griswold's "ctenoid complex" (genera Devendra, Phanotea, Machadonia, Ctenus and Phoneutria). The presence of a robust, rod-like embolus in Huntia, in contrast to the slender embolus of Janusia, probably precludes close relationship between these genera.

\section{Etymology}

The genus is named for and dedicated to our good friend and colleague, the late Glenn Hunt, former Research Associate of the Australian Museum, arachnologist and educator. The gender is male.

Huntia deepensis sp. nov.

Figures 4 d-f, 5 a-d, 6 a-d, f, g

Material Examined

\section{Holotype}

ð, Hill Top Rd, $2 \mathrm{~km}$ from turnoff on Southwest a
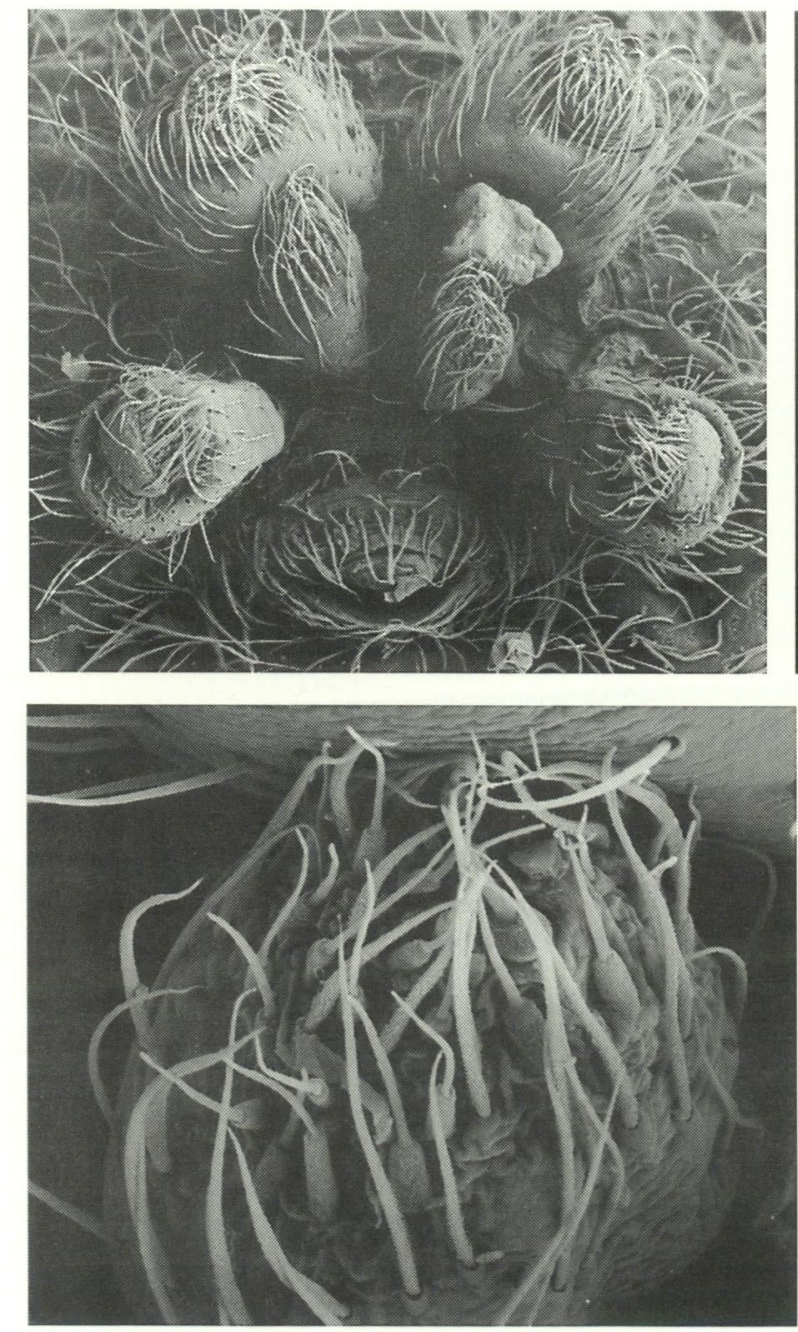

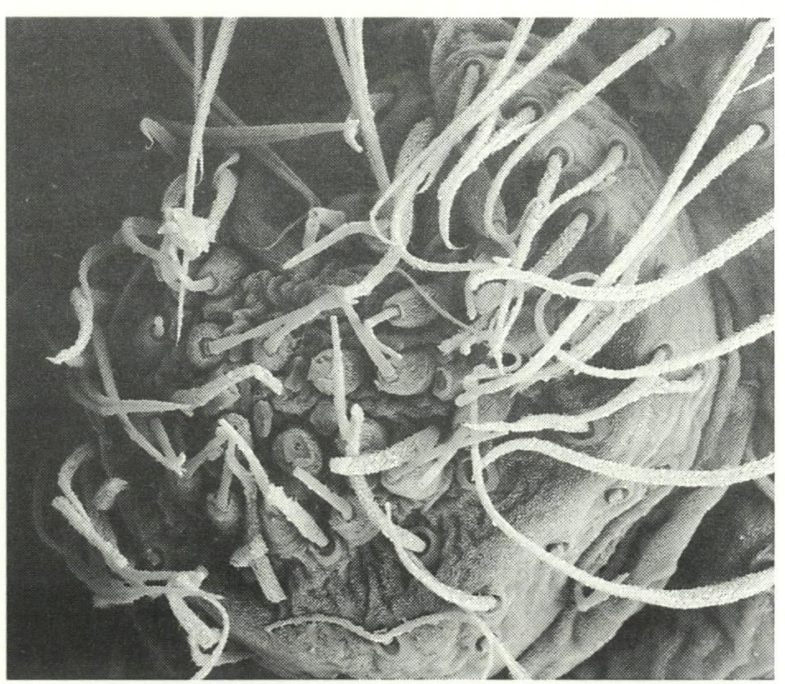

b

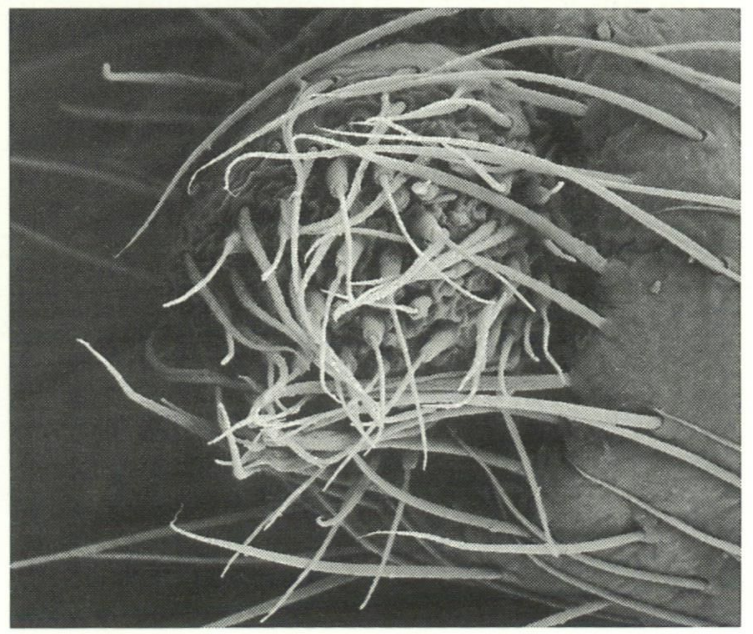

d

Figure 5 Huntia deepensis sp. nov., spinnerets (female): a, spinneret field; b, anterior lateral spinneret; c, posterior median spinneret; $d$, posterior lateral spinneret. 
Hwy, Walpole-Nornalup National Park, Western Australia, Australia, 34 $58^{\prime} \mathrm{S}, 116^{\circ} 46^{\prime} \mathrm{E}, 8$ February 1979, M.R. Gray (AMS KS 3323).

\section{Paratypes}

Australia: Western Australia: $1 q$, WalpoleNornalup National Park, Hill Top Rd, $1.9 \mathrm{~km}$ from Southwest Highway turnoff, $34^{\circ} 58^{\prime} \mathrm{S}, 116^{\circ} 46^{\prime} \mathrm{E}, 31$ January 1979, M.R. Gray (AMS KS 5957); 1 q, West Cape Howe National Park, 35 06'S,117 $37^{\circ} \mathrm{E}, 26$ April 1990, M.S. Harvey and J.M. Waldock (WAM T42364).

\section{Other Material}

Australia: Western Australia: $1 q$, near Walpole National Park, 18 July 1982, A.M. Douglas (WAM T42366); 1 \&, Torbay Head, Horton's Rd south, $35^{\circ} 08^{\prime} \mathrm{S}, 17^{\circ} 38^{\prime} \mathrm{E}, 29$ January 1979, M.R. Gray, eucalypt woodland (AMS KS5945; SEM spinnerets); 1 , Walpole-Nornalup National Park, $2 \mathrm{~km}$ along Tinglewood-Mt Clare Rd, $34^{\circ} 58^{\prime} \mathrm{S}, 116^{\circ} 46^{\prime} \mathrm{E}, 9$ February 1979, M.R. Gray (AMS KS14666); 1 q , Dog Pool on Shannon River, $34^{\circ} 48^{\prime} \mathrm{S}, 115^{\circ} 22^{\prime} \mathrm{E}, 27$ April1 May 1990, M.S. Harvey and J.M. Waldock (WAM T42365).

\section{Diagnosis}

Male with tibial crack. Embolus a robust, moderately flattened rod. Cymbium with a dorsobasal process. RTA large. Epigynal scape a broad, rounded lobe, narrow basally. PER moderately recurved. Tarsal organ capsulate, subdistal. Claw tufts absent. ITC vestigial-absent.

\section{Description}

\section{Male holotype}

Body length 9.17, CL 4.78, CW 3.37. Caput profile almost flat, highest at fovea. Legs 4213, tibia I length 1.22 times CW. Spination: leg I, femur d0110 p000011 r010, tibia v2222 p0110 r0010, metatarsus v12120 p0011 r001; leg II, femur d0111 p001011 r01100, tibia v2222 p001010 r0110, metatarsus v221 p111 r011; leg III, femur d01101 p01101 r011011, patella p010 r010, tibia d110 v222 p0110 r01010, metatarsus d111 v0222 p111 r111; leg IV, femur d0111 p00011 r011001, patella p010 p010, tibia d1010 v222 p01010 r01010, metatarsus d20002 v01212 p10101 r10001. Tibiae with tibial crack. STC with 10-11 teeth. Tarsal scopulae sparse. Palpal tibia with a small, apical, retroventral apophysis; RTA large, placed dorsad, thickest basally, tapering to a blunt, twisted apex. Cymbium ovoid, with a short, blunt apical section and a dorsobasal apophysis; dorsal cymbium with a short, fine scopula patch. Subtegular/tegular locking lobes present. Median apophysis large, deeply concave ("hood-shaped") and bimarginate, arising retrobasally. Embolus a robust, moderately curved and flattened rod, distally grooved. Conductor a hyaline lamina arising from the upper, retrolateral tegulum and placed dorsal to the distal embolus. Other characters similar to female.

\section{Female paratype (KS 5957)}

Body length 9.69, CL 5.06, CW 3.67. Carapace amber, with greyish brown patterning. Legs banded. Abdomen with a pale, narrow, dorsal stripe and grey spotted patterning, with 8 pairs of more or less distinct chevrons posteriorly. Caput profile smoothly arched. Fovea a short, deep slit. Clypeus short, the width of an AME. Chilum entire, a weakly sclerotised, triangular plate. Eyes: AME smallest. $\mathrm{AME}<\mathrm{PME}=\mathrm{PLE}<\mathrm{ALE} . \mathrm{MOQ}$ length/ width ratio 1:1.21. From above, AER slightly recurved, PER recurved; from in front, AER straight, PER slightly procurved. PER widest. Tapetum type unresolved. Chelicerae robust, weakly geniculate, with large lateral boss; 3 teeth on both retrolateral and prolateral margins. Ovoid spot of dark cuticle (?porose) behind retromarginal teeth. Medial cheliceral margin with a line of numerous, short, straight hairs. Labium longer than wide (1:0.88), basally notched, anteroventral area convex. Maxillae longer than wide, widest apically, anterolateral margins weakly concave. Sternum sub-circular, length/width ratio 1:0.90. Legs 41?23, relatively short, tibia I length 0.87 times $C W$. Cuticle finely wrinkled. Trochanters notched, shallower anteriorly, deeper posteriorly. Spination: leg I, femur d0110 p000011, tibia v2222 p0110, metatarsus v221 p001 r001; leg II, femur d0110 p01101 r01100, tibia v2222 p0110, metatarsus v221 p111 r001; leg III, femur d01111 p011110 r011110, patella p010 r010, tibia d01100 v222 p0110 r0110, metatarsus d222 v222 p111 r111; leg IV, femur d0111 p01101 r00010, patella r010, tibia d01100 v222 p0110 r0110, metatarsus d222 v11101102 p111 r111. STC with 67 teeth, ITC vestigial-absent. Claw tufts absent. Tarsi and distal metatarsi with weak scopulae. Tarsal organ subdistal, placed distal to trichobothria; capsulate, with a keyhole shaped orifice. Trichobothria staggered to form two irregular rows on tarsus; two rows on metatarsus; trichobothrial bases plicate, with 2-3 transverse ridges. Colulus indistinct. ALS and PLS short, similar in length, PMS about half as long as PLS. Epigynum with broad, lobe-like scape, lateral margins convex, narrow at base, widest across middle, posterior margin with a more or less distinct median protuberance. Lateral lobes with a large, bluntly pointed tooth arising on the posterior part of each lobe and extending back to the epigastric groove. Internal genitalia receptaculate; short copulatory ducts appear to open from atrial entrances under the anterolateral scape margins. 


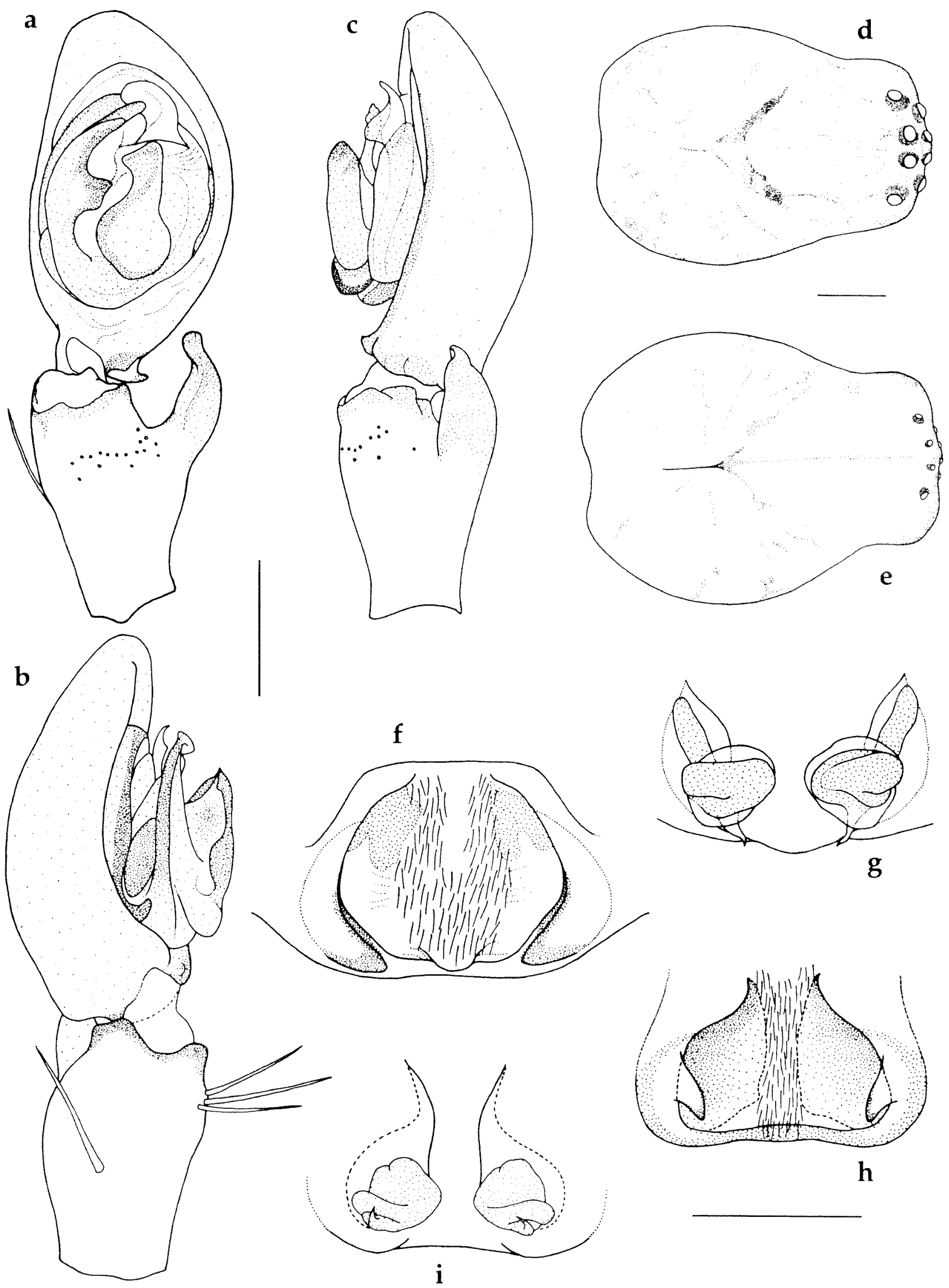

Figure 6 a-d, f, g, Huntia deepensis sp. nov., e, h, i, Huntia murrindal sp. nov. a-c, male palp: tibia, cymbium and bulb: $a$, ventral; $b$, prolateral; $c$, retrolateral. $d, e$, carapace, female. $f-i$, epigynum: $f, h$, ventral; $g$, i, dorsal. Scale lines: $a-c, f-i, 0.5 \mathrm{~mm}$; $, e, 1 \mathrm{~mm}$. 


\section{Distribution}

This species is known from the forest and woodland habitats of the Shannon River to West Cape Howe region of southern Western Australia.

\section{Etymology}

The specific epithet refers to the Deep River, Nornalup-Walpole National Park.

\section{Huntia murrindal sp. nov.}

Figures 6 e, h, i, 7 a-d

\section{Material Examined}

\section{Holotype}

, Anticline Cave, Murrindal, Victoria, Australia, $37^{\circ} 25^{\prime}$ S, $148^{\circ} 10^{\prime} \mathrm{E}, 28$ March 1970, G.S. Hunt (AMS KS17235).

\section{Paratypes}

Australia: Victoria: $1 q$, data as for holotype (AMS KS 50691); 1 \%, East Buchan, Trogdip Cave (EB10), 37 $30^{\prime} \mathrm{S}, 148^{\circ} 15^{\prime} \mathrm{E}, 13$ March 1967, E. Hamilton-Smith (SAM, BS 1570).

\section{Diagnosis}

Eyes and pigmentation reduced. Intermediate tarsal claws present. Prominent tarsal rod present, placed near mid-tarsus. Epigynal teeth subcaudal.

\section{Description}

\section{Female holotype}

Body length 9.95, CL 5.31, CW 4.10. Pigmentation greatly reduced. Carapace, sternum and legs tawny amber, darker on caput, chelicerae and distal leg segments; carapace with faint grey a
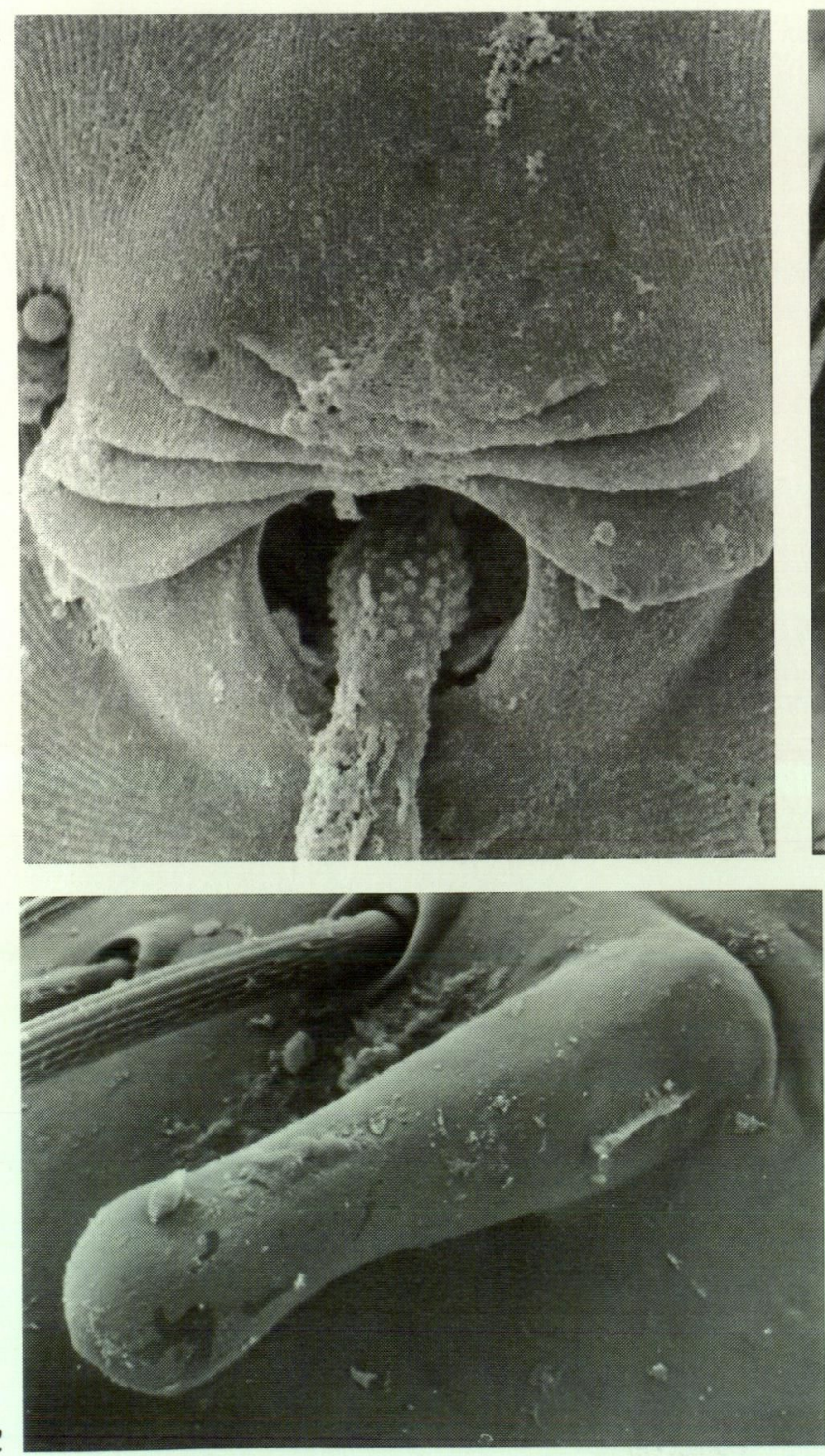

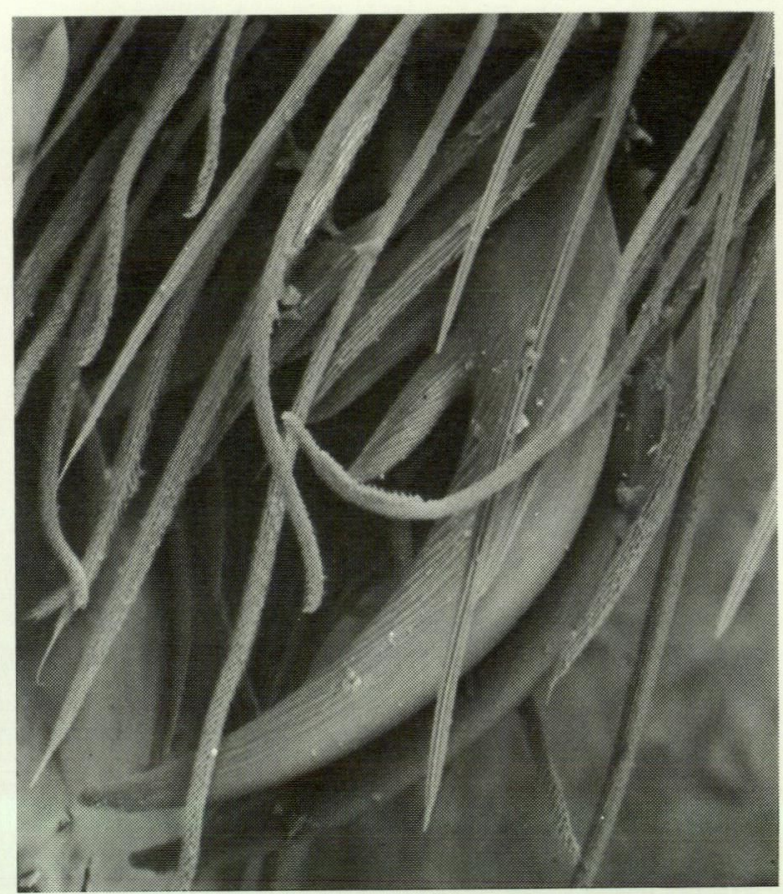

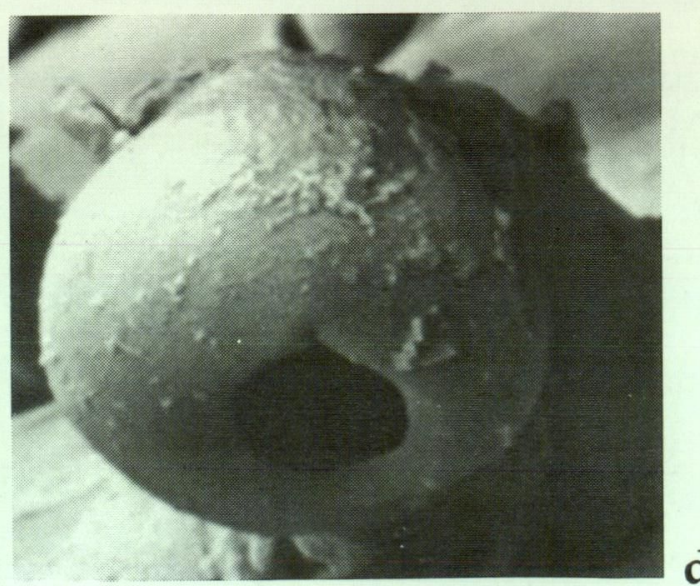

Figure 7 Huntia murrindal sp. nov., tarsus I: a, trichobothrial base; b, tarsal claws; c, d, tarsal rod. 
marginal band. Abdomen pallid grey, palest anteromedially, with one pair of small dorsal sigilla. Caput profile weakly arched, lower and flattened at fovea. Fovea an elongate slit. Eyes: all eyes reduced in size, AME smallest, probably nonfunctional (clypeus $4 \mathrm{x}$ width of an AME). From above, AER slightly recurved, PER recurved; from in front AER slightly recurved, PER straight to slightly procurved. PER widest. Tapetum type unresolved. Chilum wide, divided. Chelicerae robust, weakly geniculate, with lateral boss; promargin and retromargin with 3-4 teeth. Medial cheliceral margin with a line of numerous, short, straight hairs. Labium longer than wide (1:0.76), anteroventral area convex; with basolateral grooves adjacent to basal notches. Maxillae longer than wide, anterolateral margins shallowly concave. Sternum subcircular, length/width ratio 1:0.86, weakly pointed posteriorly. Setae plumose (sensu Lehtinen 1975), feathery hairs absent. Legs 4123, moderately long, tibia I length 1.29 times CW. Cuticle finely wrinkled. Trochanters deeply notched. Spination: leg I, femur d010101 p00011010 r001111, tibia, v22222 p01100 r001100, metatarsus v222; leg II, femur d0111011101 p0112101020 r01110101011, tibia d01010 v222222 p011021 r0011010, metatarsus v222 p110; leg III, femur d0101010 p0110110 r011110, patella p010 r010, tibia d1110 v212 p01010 r011010, metatarsus d01001 v222 p111 r1010010; leg IV, femur d01001011 p0010101 r0001011, patella p0110 r010, tibia d101010 v20202 p0110 r0101, metatarsus d101 v222 p111 r1101. Three tarsal claws with 5-7 teeth on STC, ITC smooth. Claw tufts and scopulae absent. Tarsal organ an elongate rod, placed at or proximal to the middle of the tarsus; orifice apicoventral, rounded with a very short, narrow, proximal slit. Trichobothria in two rows on tarsi and metatarsi, bases plicate with 4-5 transverse ridges. Colulus a small, hairy cone. ALS and PLS 2-segmented, PLS base robust, conical, ALS base cylindrical, both similar in length, PMS 1segmented, about half as long as PLS. Epigynal scape narrow basally, broadest posteriorly, anterolateral margins concave. Moderately large, flattened lateral teeth arise near the middle of the lateral lobes and curve posteromedially across the lateral scape margins, not reaching the epigastric groove. Internal genitalia receptaculate; atria opening under the anterolateral scape margins lead back into short, curved copulatory ducts.

\section{Distribution}

This cave adapted species is known only from the Buchan-Murrindal cave system in south-eastern Victoria.

\section{Remarks}

The placement of H. murrindal within Huntia is provisional until males become available. Taxonomic convenience is involved as a name is needed for this species because of its significance in biodiversity studies of south-eastern Australian cave systems. The species is placed in Huntia largely on the basis of sharing with $H$. deepensis a similar eye pattern, the presence of epigynal teeth and the weak development or absence of leg scopulae. Some characters seen in $H$. murrindal are markedly different from $H$. deepensis, notably the presence of three tarsal claws and a tarsal rod. However, the presence of tarsal rods and capsulate tarsal organs within the same genus has been demonstrated in Machadonia (Griswold, 1991). The different positions of the tarsal organ (subdistal in $H$. deepensis) and tarsal rod (central in H. murrindal) may suggest that these structures are not homologous.

\section{Etymology}

The specific epithet is a noun in apposition taken from the type locality.

\section{ACKNOWLEDGEMENTS}

Loan material was kindly provided by Dr Mark Harvey and Ms Julianne Waldock (Western Australian Museum) and Mr Elery Hamilton-Smith (South Australian Museum). A field trip to the caves of North West Cape peninsula was made possible by Dr Bill Humphreys, as part of his investigations of this cave system and its remarkable fauna. We thank Dr Charles Griswold (California Academy of Sciences), Ms Diana Silva (American Museum of Natural History) and Dr Robert Raven (Queensland Museum) for useful discussions on relationships.

\section{REFERENCES}

Gray, M.R. (1973). Cavernicolous spiders from the Nullarbor Plain and south-west Australia. Journal of the Australian Entomological Society 12: 207-221.

Griswold, C.E. (1991). A revision and phylogenetic analysis of the African spider genus Machadonia Lehtinen (Araneae: Lycosoidea). Entomologica Scandanavica 22: 305-351.

Griswold, C.E. (1993). Investigations into the phylogeny of the lycosoid spiders and their kin (Arachnida Araneae: Lycosoidea). Smithsonian Contributions to Zoology 539: 1-39.

Griswold, C.E., Coddington, J.A., Platnick, N.I, and Forster, R.R. (1999). Towards a phylogeny of entelegyne spiders (Araneae, Araneomorphae, Entelegynae). Journal of Arachnology 27: 53-63.

Harvey, M.S., Gray, M.R., Hunt, G.S. and Lee, D.C. (1993). The cavernicolous Arachnida and Myriapoda of Cape Range, Western Australia. In W.F. Humphreys, (ed.), The biogeography of Cape Range, Western Australia. Records of the Western Australian Museum, Supplement 45: 129-144. 
Humphreys, W.F. (Ed.) (1993). The biogeography of Cape Range, Western Australia. Records of the Western Australian Museum, Supplement 45: 1-248

Lehtinen, P.T. (1967). Classification of the cribellate spiders and some allied families, with notes on the evolution of the suborder Araneomorpha. Annales Zoologici Fennici 4: 199-468.
Lehtinen, P.T. (1975). Notes on the phylogenetic classification of Araneae. Proceedings of the $6^{\text {th }}$ International Congress of Arachnology, Amsterdam, 1974: 26-29.

Manuscript received 18 April 2000; accepted 22 February 2001. 